\title{
sciendo
}

DOI 10.2478/sbe-2019-0003

SBE no. 14(1) 2019

\section{INSTITUTIONAL ENTREPRENEURSHIP IN HEALTH MANAGEMENT: A SURVEY EXPERIMENT ON APPRECIATIVE INQUIRY®}

\author{
DEMPSTER Gregory \\ Department of Economics and Business, Hampden-Sydney College, VA, USA \\ KLUVER Jesse \\ School of Social and Behavioral Sciences, Tilburg University, The Netherlands
}

\begin{abstract}
:
Employing the lens of institutional entrepreneurship to help understand the logic of organizational change management, we conduct an analysis of the impact of Appreciative Inquiry ${ }^{\circledR}$ in a multi-unit division of a large, university-based health system. Our results indicate that, although there may have been some marginal impact in temporarily reducing an observed decline in employee commitment indicators, the program failed to sustain positive impacts over the longer term. Implications for the study of organizational change as the action of institutional entrepreneurs are briefly discussed.
\end{abstract}

Key words: Institutions, entrepreneurship, organizational change, Appreciative Inquiry ${ }^{\circledR}$, survey experiments

\section{Introduction}

Research on the implementation and impacts of particular programs in organizational change management are an important part of the process of discovering what these programs do and do not achieve, and under what conditions, as well as assisting change agents in understanding how to best implement and sustain these programs. There has been a growing interest over the past two decades in so-called "appreciative" programs for managing human relationships within organizations (Cooperrider and Srivastva, 1987; Cooperrider, et al., 2005; Boyd and Bright 2007; Mishra and Bhatnagar, 2012; Moore, Cangemi, and Ingram, 2013). Unfortunately, empirical evaluations of the impacts of appreciative methods in organizations are scarce. Most evaluative works on these methods are produced by practitioners of the methods themselves and lack both the objectivity and sophistication necessary to solicit sound judgments of their efficacy. 
This article represents an attempt to address this gap by providing an empirical case study of the application of Appreciative Inquiry $\AA$ in the context of a large, bureaucratic research-university hospital. We choose the lens of institutional entrepreneurship (DiMaggio, 1988; Dorado, 2005) through which to view the implementation of such a program. Change agents in bureaucratic settings exhibit all of the essential characteristics of institutional entrepreneurs-they work within the existing institutional framework to imagine alternative arrangements, to "reflect and act in ways other than those prescribed by taken-for-granted social rules and technological artifacts" (Garud, Hardy, and Maguire, 2007, 962). They leverage resources within the organization in order to bring about changes in existing institutions by transforming or replacing them, with the goal of achieving highly-valued, but previously unrealized, interests (Maguire, Hardy, and Lawrence, 2004). In doing so, they often must create new systems of meaning that bind the institutional system together (Garud, Jain, and Kumaraswamy, 2002). These activities represent a convincing description of what change agents, particularly those working in the context of appreciative approaches, seek to accomplish for the organizations they operate within. Organizational change agents are institutional entrepreneurs; as such, they must develop strategies to embed new institutional structures within diverse organizational fields. Thus, their efforts are often intensely political in nature (Fligstein, 1997; Garud, Hardy, and Maguire, 2007).

Research into this area of change management is important for at least two reasons. First, there is a need for empirical research to establish benchmarks for the effectiveness of organizational change programs such as Appreciative Inquiry ${ }^{\circledR}$ (Todnem, 2005). Second, given the high failure rate of organizational change initiatives, research into what goes wrong when change management fails can be as instructive as when it succeeds (Beer, et al., 1990). Our research focuses on both the short-term and long-term impacts of efforts by institutional entrepreneurs to embed habits of appreciative learning and leadership in a highly-diverse bureaucratic setting. The results are mixed: While we find evidence of short-run, positive impacts that seem to stem a downward trend in important indicators of employee commitment to the organization, no positive long-run impact can be found. In what follows, we first describe the background of our approach and the characteristics of the firm we are analyzing; next, we provide a description of the methods we use to ascertain short-run and long-run impacts; and, finally, we discuss the implications of our findings.

\section{Background}

Appreciative Inquiry ${ }^{\circledR}$ (hereafter $\mathrm{Al}$ ) is an approach to organizational change management that seeks to increase organizational performance by building trust among organizational constituents through a program of "positive" and "life-affirming" approaches to organizational and group change (see Cooperrider and Whitney, 1999; Bushe, 2011; and Appreciative Inquiry Commons, 2012). The approach stems from the research of Cooperrider and Srivastra (1987) and has spawned a set of practices for organizational change that hundreds of organizations are applying or have attempted to apply. Our intent 
is to use a specific case of Al application to explore the nature of institutional entrepreneurship in practice within large, bureaucratic organizations.

Research in institutional entrepreneurship has proliferated since DiMaggio (1988) first introduced the term to describe agents that mobilize resources to create or transform institutions in order to further their interests (see, e.g., Fligstein, 1997; Beckert, 1999; Kraatz and Moore, 2002; Sherer and Lee, 2002; Greenwood, Suddaby and Hinings, 2002; Phillips and Tracy, 2007; Battilana and Leca, 2009; Battilana, Leca, and Boxenbaum, 2009; and Droege and Marvel, 2010). A parallel literature, focusing on the intentionality of institutional actors rather than the structures in which their action occurs, has developed in the property rights literature in economics over a longer period of time (see, e. g., Olson, 1965; Demsetz, 1967; Anderson and Hill, 1975; North, 1990, 1991; North and Weingast, 1989; and Ostrom, 2000). As highlighted by Pacheco, et al. (2010), these strands are at once both complementary and unlinked in the literature. The current article represents one attempt to integrate these perspectives, focusing on the institutional structure that helps determine attitudes, perceptions, and expectations within healthcare organizations, as well as on the incentives for purposeful action toward modifying these attitudes, perceptions, and expectations and the structures that influence them.

Institutional entrepreneurship represents "the activities of actors who have an interest in encouraging particular institutional arrangements and who leverage resources to create new institutions or to transform existing ones" (Bruton, Ahlstrom and Li, 2010, p. 429). As such, it must confront the formal mechanisms of legal sanction and organizational bureaucracy as well as the informal mechanisms of social and organizational norms and legitimacy. Baumol (1990, 2009), de Soto (2000), and others have highlighted the importance of institutional contexts in promoting both productive and unproductive forms of entrepreneurial activity. In the management and sociology literatures, scholars have explored the nature of trust in organizational settings and the importance of social capital in maintaining efficient collective action.

The institutional economics literature addresses institutional change at three levels (Williamson, 2000; Pacheco, et al., 2010): Socially embedded rules and norms, formal laws and rights, and governance mechanisms (see, e.g., Anderson and Hill, 1975; Eggertsson, 1996; Harris, 1997; Greif, 1998; Ostrom, 2000; and Tan, 2005). Scholars in institutional economics are increasingly focusing on the highest level, encompassing "the role of institutions such as ideology, culture, cooperation, and the emergence of group norms," particularly in the context of game theory (Pacheco, et al., 2010, p. 983). Institutional economics has been rather slow, however, in incorporating models of trust into entrepreneurship research, despite its prevalence in the economics literature on property rights and corruption (Shleifer and Vishney, 1993; Mauro, 1995). Likewise, although trust is often incorporated into sociological models of behavior, new institutionalism has tended to focus on the isomorphic characteristics of culture and norms, rather than the ways in which entrepreneurs attempt to build trust in accordance with value-creating opportunities for institutional change. Researchers in this stream of entrepreneurial studies often refer to the paradox of embedded agency, which expresses the problem of novelty and innovation within organizational fields where dominant actors, who benefit the most from maintaining 
existing institutional structures, have little motivation to contemplate change (Garud, Hardy, and Maguire, 2007; Battilana and D'Aunno, 2009).

Bushe and Marshak (2009) describe Al as one of a number of emerging "dialogic" practices for organizational development and change. The Al process focuses on a fourphase model of Discovery, Dream, Design, and Delivery, often referred to as the 4D program. An underlying premise is that reinforcing positive, affirming values, spirit, and behavior (Oliver, Fitzgerald and Hoxsey, 2011) will produce enduring positive outcomes in organizational life. The approach seeks to induce change on "the foundation of what works, what empowers, what motivates, what gives hope and what inspires change and innovation" (Mann, 2011, 13). According to Cooperrider (1990), one of the nominal founders of the approach, creating "the conditions for organization wide appreciation is the single most important measure that can be taken to ensure the conscious evolutions of a valued and positive future" (52). Thus, Al as an overall approach is firmly committed to the roles of appreciating the skills, talents, abilities and values of those that contribute to the organization; envisioning what the organization could be if all of those skills, talents, abilities and values were utilized; sustaining the viability and success of the organization by channeling this vision toward positive, continuous change; and co-constructing the organizational future by means of a participative process of inquiry and direction. These four points roughly correspond to the 4D program in action.

The Al process has been employed by many hundreds of organizations since its inception just over 20 years ago. Little research has been done, however, on uncovering the true impact of the application of Al to organizational change. The few exceptions to this rule are mostly qualitative in nature and often are conducted by practitioners themselves (the Al "community") rather than by disinterested observers of the process (see, e.g., Oliver, Fitzgerald and Hoxsey, 2011; Mann, 2011; Jacobsgaard and Norlund, 2011; Magruder Watkins, 2011; Nelson and Wright, 2011; and Whitney, 2010). There is a lack of rigorous, systematic, and objective research in regard to whether, and under what conditions, the Al process actually delivers what is promised in comparison to more traditional problem-solving approaches to organizational change (i). We aim to address this in the context of a particular case of an Al application in a division of a large, university-based health system experiencing problems related to trust and communication in the work environment. Furthermore, we hope to shed light on the usefulness of an expectations-oriented framework to answer questions about methods of institutional entrepreneurship and the effectiveness of institutional change initiatives within bureaucratic organizations.

\section{Methods}

\section{Case Study Characteristics}

The University Health System (UHS) is a University-based medical system operating at a large, prestigious mid-Atlantic institution. The UHS operates a full service hospital, the University Medical Center, as well as a number of inpatient and outpatient facilities throughout the state. One of these outpatient service providers is the Renal Services Division (RSD), which administers dialysis and other crucial services to state 
residents on campus and at a variety of centers in the surrounding area. The RSD is among the first divisions of the UHS to undergo an organization-wide Al program aimed at addressing problems of service quality, job satisfaction, and morale throughout the system. Problems within the system had been well documented and diagnosed by management for a number of years, and many of these problems suggest an organizational performance that fits well with the "low-expectations" equilibrium conditions outlined above. Organization-wide scores on regularly administered employee surveys for matters of job satisfaction, inclusiveness in decision making, work climate, communication, and the like had been low relative to nationwide benchmarks. In the 2008 administration of this survey, more than $20 \%$ of employees had an unfavorable opinion of pay, decision involvement, staffing, recognition, work climate, and work communication within the UHS. The Commitment Indicator Score, which is a composite of survey questions relating to the degree of commitment employees fell toward the workplace, was routinely below the national averages against which UHS benchmarked itself. The survey-level evidence from the UHS suggests that the "low-expectations equilibrium" is an apt description of the conditions in the organization.

Table 1 presents some of the issues highlighted in the annual employee survey of 2008 , which is representative of previous annual surveys. The reported results come from a sub-set of questions known as Power, Readiness and Commitment Indicators, which relate directly to the attitudes of employees within the organization towards management, fellow employees, and the organization as a whole. Average ratings are on a 5-point scale, from Strong Agreement (5) to Strong Disagreement (1), and a standard deviation of about .20 is assumed for evaluation purposes by the management, such that scores $<3.8$ are considered out of acceptable range. The results are also benchmarked to a national average of similar institutions for further evaluative clarity. Among the noteworthy inferences that one can draw from a cursory review of these survey responses is that almost all (23 of 24 ) average responses are low relative to the benchmark.

Table 1: Average Responses to Commitment Indicators, 2008.

\begin{tabular}{l|c} 
Survey Item & $\begin{array}{l}\text { Score } \\
\text { (+/- from benchmark) }\end{array}$ \\
$\begin{array}{l}\text { University Health System supports me in balancing my work life and personal } \\
\text { life. }\end{array}$ & $3.50(-0.27)$ \\
\hline University Health System provides career development opportunities. & $3.78(+0.07)$ \\
\hline My pay is fair compared to other healthcare employers in this area. & $2.94(-0.24)$ \\
\hline University Health System treats employees with respect. & $3.48(-0.28)$ \\
\hline Different work units work well together at University Health System. & $3.41(-0.09)$ \\
\hline University Health System conducts business in an ethical manner. & $3.82(-0.23)$ \\
\hline University Health System provides high-quality care and service. & $3.98(-0.18)$ \\
\hline My job makes good use of my skills and abilities. & $3.94(-0.14)$ \\
\hline I like the work I do. & $4.35(-0.12)$ \\
\hline My work unit works well together. & $3.99(-0.02)$ \\
\hline I am satisfied with the recognition I receive for doing a good job. & $3.33(-0.20)$ \\
\hline
\end{tabular}




\begin{tabular}{l|c|} 
I am involved in decisions that affect my work. & $3.41(-0.23)$ \\
\hline My department manager treats me with respect. & $4.13(-0.06)$ \\
\hline I respect the abilities of my department manager. & $4.03(-0.14)$ \\
\hline My department manager is a good communicator. & $3.80(-0.07)$ \\
\hline My department manager supports free exchanges of opinions and ideas. & $3.90(-0.12)$ \\
\hline My department manager encourages teamwork. & $4.02(-0.05)$ \\
\hline My department manager cares about my job satisfaction. & $3.82(-0.10)$ \\
\hline I am proud to tell people I work for University Health System. & $4.03(-0.19)$ \\
\hline I would recommend University Health System to family and friends who need \\
care.
\end{tabular}

Although we lack the summary statistics on variance that would allow us to perform standard significance test on the individual components, it is highly unlikely that so many responses would fall below the benchmark on the basis of random variation alone. On the basis of results from annual surveys such as this one, UHS identified a number of work units that failed to reach a level of acceptable performance on the Power, Readiness, and Commitment Indicators scores. One such unit was RSD. Although the precise scores for the RSD unit were not provided to the researchers, it is assumed that overall averages fell well outside the assumed standard deviation range and/or well below benchmarks.

RSD is a fairly decentralized division due to the large number of regional offices, which are necessitated by its provision of dialysis and other services in community-based centers. For the Al process, these centers were placed into two regional hubs, and the $\mathrm{Al}$ program was administered on a hub-by-hub basis, with two or three tracks within each hub to ensure that services were not unduly interrupted. Thus, it was possible for us to trace the results of the Al process on a pre-post basis for two different administrations, allowing us to make some cross-wise comparisons that would have been impossible if it had been administered all at once.

\section{Theory, Hypotheses, and Empirical Design}

At its most basic level, any program of large scale institutional change represents an attempt to change the "initial conditions" governing organizational perceptions and expectations in such a way that day-to-day interactions among stakeholders will produce incremental improvements in the capacities of the organization to fulfill its goals, or its effectiveness. One convenient way of conceptualizing the problem of institutional change is a multiple-equilibrium framework (see, e.g., Todaro and Smith, 2011, 159-162). In this framework, the institutional conditions of the organization determine the most efficient courses of actions for individual stakeholders within the micro-organizational system, which in turn lead to macro-organizational outcomes that may be positive or negative in relation to its goals. So, for example, if individual stakeholders have low expectations of the 
willingness of others to sacrifice for the collective benefit of the organization, or negative perceptions of the intentions and motivations of other stakeholders (management, employees, etc.), they will be unwilling to expend valuable resources of time, effort, and the like toward an outcome that is, at best, uncertain and at worst, destined to be suboptimal. Thus, the collective action problem becomes a problem of "who goes first" in terms of putting forth an effort that is subject to free-riding of other stakeholders.

Our empirical work focuses on the dynamics of the Al process as it unfolds within an organization and its subunits and seeks answers to questions concerning the impact of Al on employee satisfaction, relationships and performance. We draw from a speciallydesigned pre-post survey for employees in a subunit administered as the Al process unfolded, in order to test hypotheses about $(A)$ whether $A$ l has discernible, positive effects on variables related to successful organizational outcomes, $(B)$ whether the management of expectations plays an important role in determining those outcomes, and conditioned on these results, (C) whether the $\mathrm{Al}$ process effectively managed expectations in the experimental case we are examining. More formally, our hypotheses can be stated as follows:

H1: Al has a positive, statistically significant effect on measures that management considers important for organizational success.

$\mathrm{H} 2$ : $\quad$ The addition of variables that measure latent employee expectations will further illuminate the impact of Al by indicating positive effects on employee expectations.

$\mathrm{H} 3$ : Expectations management is an aspect of a "successful" Al intervention within an organizational unit or subunit, as indicated by positive relationships (covariance) between $\mathrm{Al}$ and an expectations-augmented set of organizational commitment indicators.

Two cohorts, based on Northern and Southern regional groupings, were segmented in order of when the Al "interventions" would take place, with the Southern cohort going through the process first (September, 2010) and the Northern one afterwards (October, 2010). The complete survey consisted of the 24 Commitment indicators in Table 1 above, plus 12 additional Expectations indicators relating to their level optimism about the intentions and capabilities of coworkers, supervisors, and organizational management (available on request). Answers were placed on a scale of 1-9, rather than 1-5 as in the original survey, with 9 indicating strongest agreement and 1 indicating strongest disagreement. The survey was administered to each full cohort three times. For the Southern cohort, the first administration took place in early September prior to the beginning of the Al workshops; the second administration was given immediately following the Al workshops; and the third administration was given in early October after all units in the cohort had completed the Al process. Thus, for the Southern cohort, Round 1 is a "pre-intervention" marker, while Rounds 2 and 3 are "post-intervention" markers. For the Northern cohort, the first administration took place in early September at the same time as the Southern cohort's Round 1; the second administration was given in early October at the same time as the Southern cohort's Round 3, but before any workshops had been run for the Northern work units; and the third and final administration was given immediately following the Al workshops for that cohort. Thus, for the Northern cohort, Round 1 and Round 2 are both "pre-intervention" markers, with Round 2 representing a "control" on the 
Southern cohort's "post-intervention" Round 2, while Round 3 is a "post-intervention" marker like the Southern cohort's Round 3.

Table 2: Sequence of Al Interventions, by RSD Cohort.

\begin{tabular}{lll} 
& \multicolumn{1}{c}{ Southern } & \multicolumn{1}{c}{ Northern } \\
Round 1 & Pre-intervention & Pre-intervention \\
Round 2 & Post-intervention & Pre-intervention \\
Round 3 & Post-intervention & Post-intervention
\end{tabular}

By administering the surveys in this fashion, we set up our experiment to potentially reveal impacts in two ways: As differences in commitment and/or expectations between cohorts as they moved from Round 1 to Round 2; or as changes in commitment and/or expectations in both groups as they moved from Round 1 to Round 3 . In essence, we have a controlled (or restricted) model that focuses on the differences between survey results from the two cohorts as one of them (Southern) goes through the Al process and the other (Northern) doesn't, and an uncontrolled (unrestricted) model which focuses on how survey results change regardless of the order in which the interventions took place. We hereafter refer to these models as the restricted and unrestricted models, respectively.

\section{Data and Results}

There were 159 valid surveys completed in Round 1 (104 Southern, 55 Northern); 151 completed in Round 2 (95 Southern, 56 Northern); and 99 completed in Round 3 (75 Southern, 24 Northern).' We compiled the mean scores for each of our 36 survey questions by cohort for each of the three time periods (rounds). Data is available in Excel format by request. The three hypotheses we have formulated are represented conceptually in Figure 1 below.

Our structural model focuses on the relationships between latent attitudes and beliefs about coworkers, the work environment and benefit levels, and observed variables from survey data that indicate levels of another latent variable, Commitment to the Organization (CO). These observed variables are thought to have systematic effects on employee retention, productivity and performance, and it is these observed relationships that UHS intended to exploit by using an Al intervention process to positively impact organizational commitment scores. We posit that these attitudes about coworkers, the work environment and remuneration impact the $\mathrm{CO}$ scores directly, and thus, an intervention process like $\mathrm{Al}$, designed to impact these latent variables, should result in greater CO scores as it unfolds. Hypothesis (1) above relates to the evidence of direct impacts from the Al process on commitment scores. 


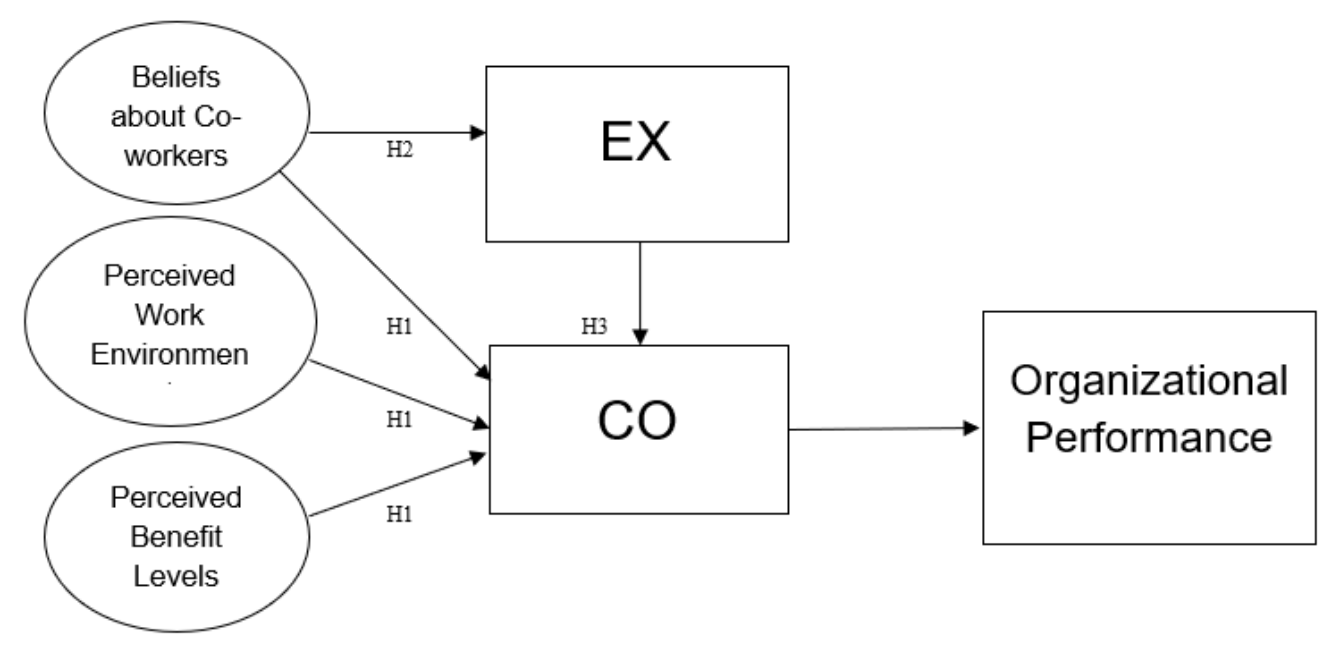

Figure 1. Structural Model of Impacts on Organizational Commitment (CO)

Hypotheses (2) and (3) above suggest that there is additional possible source of covariance between employee beliefs and observed commitment scores. If expectations (EX) about the capabilities and intentions of coworkers, supervisors, and top managers are an important element of decision making by employees regarding their level of work effort, then attitudes about coworkers may represent, in part, rational responses to an "expectational" equilibrium in the workplace; in other words, employees attitudes are informed, in part, by a rational (though not necessarily conscious) calculus about what can and cannot be expected of their coworkers and the organization in which they work. If this is true, then adding measures of those expectations to our basic model should improve the model's explanatory power. Thus, Hypothesis (2) can be tested by estimating the value of the intervention on a latent expectations score and testing against a null of zero. Hypothesis (3) would extend this idea by testing whether the expectations-augmented measures lead to statistically significant changes in organizational commitment indicators on a pre-test vs. post-test basis, as measured by covariance between the time-specific intervention between time periods 1 and 2. The observed variables are the mean participant scores for each question in the Expectations (EX) and Commitment (CO) indicator surveys in each cohort at each time period (1,2 and 3). We test these three hypotheses in reverse order, as outlined in the following subsections.

\section{Preliminary Tests: Short-Run Impacts}

For the restricted model over Rounds 1 and 2, the scores for each of the 36 survey questions are averaged by cohort, designated SOUTH and NORTH, along with other summary statistics, in Table 3 below. 
Table 3: Summary Statistics for Responses to All Questions, by RSD Cohort, 2010. ROUND 1: ROUND 2:

$\begin{array}{llllll} & \text { SOUTH } & \text { NORTH } & & \text { SOUTH } & \text { NORTH } \\ \text { Mean } & 6.520 & 6.366 & \text { Mean } & 6.343 & 5.836 \\ \text { Median } & 6.573 & 6.302 & \text { Median } & 6.351 & 5.593 \\ \text { Std. Dev. } & 0.463 & 0.426 & \text { Std. Dev. } & 0.357 & 0.520 \\ \text { Skewness } & -0.521 & 0.491 & \text { Skewness } & 0.161 & 0.794 \\ \text { Kurtosis } & 0.632 & -0.042 & \text { Kurtosis } & 0.471 & 0.037\end{array}$

These summary statistics represent the short-run impacts of an Al intervention in the SOUTH group relative to the NORTH control group. The data suggest that overall attitudes about current and future organizational performance at UHS seemed to decline over the observation period, for reasons unknown to the researchers (these results hold even if we focus only on survey questions regarding commitment or, alternatively, on those regarding expectations). Both the mean and median values for each cohort reflect a highly significant, negative change from Round 1 to Round 2. However, this decline in attitudes is much more pronounced in the Northern cohort than in the Southern one. We can abstract away from the overall trend by focusing on differences between trends in the southern cohort, within which the Al process had been started, and those in the still pre-Al northern control group. A z-test for difference in differences (DID) between the mean values of the two cohorts indicates a highly significant change from Round 1 to Round 2 ( $z$-score $=5.96$; $p$-value $\left.=0.01 e^{-7}\right)$. This result holds even if we segment the questions into those focusing on commitment and those focusing on expectations, indicating that it is pervasive regarding all of our measures of employee attitudes. Put simply, we can reject the null hypothesis of no change in the relation of attitudes between cohorts from Round 1 to Round 2. Attitudes in the post-Al Southern cohort are considerably more favorable, relative to the still pre-AI North cohort, in Round 2 than they were in Round 1.

As for the unrestricted pre-post model, we are somewhat limited by the fact that some of our Round 3 data was miscoded (ii). However, we can make a few inferences from the data we have. ANOVA tests for differences in mean values do not indicate any significant difference in the values reported for all 36 survey questions between Rounds 1 and 3 for either cohort. However, the picture changes somewhat when we segment the questions into those that focus on commitment and those focusing on expectations. Recalling that both cohorts indicated a statistically-significant negative trend from Round 1 to Round 2, though less pronounced for the southern cohort, one might wonder what caused the recovery in values from Round 2 to Round 3, particularly in the northern cohort. Z-values of the 12 expectations questions indicate a marginally-significant change from Round 1 to Round 3 (z-score $=1.56 ; \mathrm{p}$-level $=.12$ ). In other words, although overall employee perceptions (expectations and commitment) do not appear to have been improved in the short-run by the Al process, employee expectations regarding the intentions and capabilities of others toward improving future performance may have been impacted positively enough to offset a more general, severe downward trend in the northern cohort. Table 4 below contains summary statistics for these 12 questions averaged for the northern cohort. 
Table 4: Summary Statistics for Responses to Expectations Indicators, Northern Cohort, 2010

$\begin{array}{llll} & \text { ROUND 1 } & & \text { ROUND 3 } \\ \text { Mean } & 6.272 & \text { Mean } & 6.417 \\ \text { Median } & 6.172 & \text { Median } & 6.259 \\ \text { Std. Dev. } & 0.252 & \text { Std. Dev. } & 0.524 \\ \text { Skewness } & 0.620 & \text { Skewness } & 0.431 \\ \text { Kurtosis } & 1.930 & \text { Kurtosis } & 1.681\end{array}$

These results are highly preliminary, and the data coding issues hinder our analysis and interpretation of the results. However, there is some evidence of a moderate, positive impact of the Al intervention at UHS, and this impact includes the effect of the program on the expectation of employees in regard to the intentions and competence of their fellow employees, their managers, and the UHS in general. The evidence is strengthened by the limited qualitative data available. For example, a human resources manager in the Health Services Foundation, which employs the physicians who work in the Medical Center of the UHS, credits the Al program with "real business results" that included better teamwork in getting projects done "faster, better, [with] better communication." (Brennan, 2010, personal communication). Further investigation is necessary before we can come to any firm conclusions about this interesting case study in organizational change. However, these preliminary results are taken to indicate some support for Hypotheses (2) and (3) above, namely that (a) including measures of employee expectations improves the explanatory power of Al's impact on employee behavior over the sample period $(\mathrm{H} 2)$, and that pre-post analysis of an $\mathrm{Al}$ intervention, relative to a control group, indicates a significant, positive short-term impact on organizational commitment $(\mathrm{H} 3)$. Longer-term impacts indicated by Hypothesis (1) require further analysis, as attempted in the next section.

\section{Long-Run Tests and Results}

As previously explained, we posit that attitudes about coworkers and the work environment impact the $\mathrm{CO}$ scores directly, and thus, an intervention process like Al, designed to impact these latent variables, should result in greater $\mathrm{CO}$ scores as it unfolds. Hypothesis (1) above relates to the evidence of direct impacts from the Al process on commitment scores. We can test Hypothesis (1) by estimating the impact of $\mathrm{Al}$ on our observed commitment proxies and comparing to a null of no change in the means of those impacts between the pre- and post-intervention period for both cohorts. Importantly, this will provide more information than our short-run ANOVA tests by incorporating impacts of unobserved, time-related factors. If impacts from Al are persistent, there should be an observable difference in $\mathrm{CO}$ scores from one year to the next.

We obtained a sample of data from RSD employees on a new 2011 system-wide survey on employee engagement. The 2011 survey is not, unfortunately, identical to the original 2008 survey from which we drew our Commitment indicator questions. However, there is significant overlap between the two surveys, with many of the same questions. 
Furthermore, most non-matching questions on the 2011 survey have a close equivalent among the $24 \mathrm{CO}$ indicators from our original survey, so that we are able to construct a sample of questions that are essentially measuring equivalent attitudes across the two surveys. We found that, of the 24 original indicators in the 2010 survey, three-quarters (18) have equivalent or near-equivalent indicators in the 2011 survey. (These "equivalent" 2011 survey questions are included in the appendix to this paper.) A total of 392 valid surveys were reported in 2011, over twice as many as we were able to gather in our initial 2010 pre-Al administration.

The 2011 survey results are reported on a mean percentile basis, which requires that we convert the mean score for each question into our 1-9 scale by multiplying the percent score by nine. For example, a mean score of $80 \%$ would be converted to our 2010 scale by multiplying $.80^{*} 9=7.2$. Thus, combining our initial pre-intervention survey in 2010 with this new 2011 post-intervention survey, we have constructed a complete set of preand post-intervention data for RSD on 18 of the primary Commitment (CO) indicators from Table 1. Descriptive statistics for comparisons of the 2011 data with our 2010 baseline are provided in Table 5 below.

A two-tailed test for differences in mean indicates a marginally-significant but negative change $(z$-score $=1.70 ; p$-value $=.09)$ in the mean response. This represents a reversal of our short-run results. Of course, given the less than perfect equivalence of the commitment indicators employed in the two surveys, this could be an artifact of the data, and not indicative of any actual trend. Likewise, the larger number of completed surveys for the 2011 period may indicate that the earlier results may have been less than representative of the larger employee population at RSD. Nonetheless, it is clear that there is no evidence that promising short-run indications were sustained over the longer-term, and our earlier findings of a general downward trend in commitment indicator scores suggests that those trends have continued despite attempts to promote Al within the RSD.

Table 5: Summary Statistics for Responses to Commitment Indicators, All RSD Cohorts, 2010 (Round 1) and 2011.

$\begin{array}{lclc} & 2010 & & 2011 \\ \text { Mean } & 6.525 & \text { Mean } & 6.444 \\ \text { Median } & 6.562 & \text { Median } & 6.436 \\ \text { Std. Dev. } & 0.462 & \text { Std. Dev. } & 0.600 \\ \text { Skewness } & -0.308 & \text { Skewness } & 0.352 \\ \text { Kurtosis } & 3.260 & \text { Kurtosis } & -0.656\end{array}$

Are the results an indication that Al has failed? Without more detailed data, we can only speculate. Perhaps the change agents who were attempting to embed new expectations by using appreciative methods were thwarted by external events, lack of resources, or active resistance from entrenched interests. Additional data would be helpful in determining whether the cause is faulty implementation, an inappropriate construct, external events, or some combination of those. Unfortunately, with regard to long-run impacts, we are left with more questions than answers about the effectiveness of Al. 
However, our results are not without use; we can confidently say that objective evidence for persistent, beneficial impacts of institutional change are lacking in this particular case. Institutional entrepreneurs, like all entrepreneurs, operate on a continual basis of action and feedback. Those working to affect change within complex institutional contexts need to know when their efforts fail to produce the desired impacts, so that they can examine the situation objectively and, perhaps, learn why those efforts did not succeed. Further empirical research on the success and failures that institutional entrepreneurs experience, as well as the obstacles they face, will move us forward in designing change programs.

\section{Conclusions}

We have conducted one of the few systematic examinations of the implementation of Appreciative Inquiry $\circledast$, a program of organizational change designed to emphasize the positive aspects of employee contributions to organizational life and to capitalize on those aspects to produce positive outcomes in terms of employee relationships and commitment. Our findings indicate a set of mixed results-there is some indication that Al mitigates negative trends in employee commitment in the short-run, but, unfortunately, long-run trends in employee commitment for this health management organization remained negative over the intermediate term. While far from the final word on the efficacy of these programs, we hope that, in the least, these results will offer some impetus for reflection and discussion about what these and similar programs of organizational change offer, and how change agents might proceed to employ them more effectively in the bureaucratic setting of large organizations.

Bushe and Kassam (2005) suggest that it may be the manner in which Al is administered that matters for whether an Al program is "transformative" in the sense of achieving positive results. Although our study finds no evidence of positive, long-run impacts, we were unable to control for factors that might indicate the reasons for their absence. Perhaps comparative, longitudinal studies among organizations that administer $\mathrm{Al}$ in different, measurable ways might be the key to uncovering the true potential for $\mathrm{Al}$ as a transformative means of organizational change management.

\section{References}

Anderson, T. and Hill, P. (1975). The evolution of property rights: A study of the American West. Journal of Law \& Economics, Vol. 18, no. 1, pp. 163-179.

Appreciative Inquiry Commons (2012). http://appreciativeinquiry.case.edu/intro/vision.cfm. Last accessed on December 6, 2012.

Battilana, J. and D'Aunno, T. (2009). Institutional work and the paradox of embedded agency. In

T. Lawrence, R. Suddaby and B. Leca (Eds.), Institutional Work: Actors and Agency in Institutional Studies of Organizations, pp. 31-58. Cambridge, U.K.: Cambridge University Press.

Battilana, J., and Leca, B. (2009). The role of resources in institutional entrepreneurship: Insights for an approach to strategic management combining agency and institutions. In L. A. Costanzo and R. B. MacKay (Eds.), Handbook of Research on Strategy and Foresight, pp. 260-274. Norwell, MA: Kluwer.

Battilana, J., Leca, B., and Boxenbaum, E. (2009). How actors change institutions: Towards a theory of institutional entrepreneurship. Academy of Management Annals, Vol. 3, no.1, pp. 65-107. 
Baumol, W. (1990). Entrepreneurship: Productive, unproductive, and destructive. Journal of Political Economy, Vol. 98, no. 5, Part 1 (Oct.), pp. 893-92.

Baumol, W. (2009). Entrepreneurship, trade competition and the explosion of world trade, Chapter 1 in David B. Audretsch R. L. and R. J. Strom, eds., Entrepreneurship and Openness: Theory and Evidence, pp. 13-23. Cheltenham, UK: Edward Elgar Publishing.

Beer, M., Eisenstat, R. and Spector, B. (1990). Why change programs don't produce change. Harvard Business Review, Vol. 68, no. 6, pp. 158-166.

Beckert, J. (1999). Agency, entrepreneurs, and institutional change: The role of strategic choice and institutionalized practices in organizations. Organization Studies, Vol. 20, no. 5, pp. 777799.

Boyd, N. and Bright, D. (2007) Appreciative inquiry as a mode of action research for community psychology. Journal of Community Psychology, Vol. 35, no. 8, pp. 1019-1036.

Bruton, G., Ahlstrom D. and Li, H. (2010). Institutional theory and entrepreneurship: Where are we now and where do we need to move in the future? Entrepreneurship Theory and Practice, Vol. 34, no. 3, pp. 421-440.

Bushe, G. and Coetzer, G. (1995). Appreciative inquiry as a team-development intervention: A controlled experiment. Journal of Applied Behavioral Science, Vol. 31, no. 1, pp. 13-30.

Bushe, G. and Kassam, A. (2005). When is Appreciative Inquiry transformational? A meta-case analysis. Journal of Applied Behavioral Science, Vol. 41, no. 2, pp. 161-181.

Bushe, G. and Marshak, R. (2009). Revisioning organization development: Diagnostic and dialogic premises and patterns of practice. Journal of Applied Behavioral Science, Vol. 45, no. 3, pp. 345-365.

Bushe, G. (2011). Appreciative inquiry: Theory and critique. In Boje, D., Burnes, B., and Hassard, J. (eds.), Routledge Companion to Organizational Change, pp. 87-103. Oxford, UK: Routledge.

Carter, B. (2006). 'One expertise among many'- Working appreciatively to make miracles instead of finding problems. Journal of Research in Nursing, Vol. 11, no. 1, pp. 48-63.

Cooperrider, D. (1990). Positive image, positive action: The affirmative basis of organizing. In Srivastva, S., Cooperrider, D. (Eds.), Appreciative Management and Leadership: The Power of Positive Thought and Action in Organizations. San Francisco, CA: Jossey-Bass, Inc.

Cooperrider, D. and Srivastva, S. (1987). Appreciative Inquiry in organizational life. In W. Pasmore \& R. Woodman (Eds.), Research in Organization Change and Development, Vol. 1, pp. 129169. Greenwich, CT: JAI Press.

Cooperrider, D., Whitney, D. (1999). Appreciative Inquiry: A positive revolution in change. In Holman, P., Devane, T. (Eds.), The Change Handbook: Group Methods for Shaping the Future. San Francisco, CA: Berrett-Koehler Publishers, Inc.

Cooperrider, D., Sorenson, P., Yeager, T. and Whitney, D. (2005). Appreciative Inquiry: Foundations in Positive Organization Development. Champaign, IL: Stripes.

Dorado, S. (2005). Institutional entrepreneurship, partaking, and convening. Organization Studies, Vol. 26. pp. 385-414.

Demsetz, H. (1967). Towards a theory of property rights. American Economic Review, Vol. 57, pp. 347- 359.

De Soto, H. (2000). The Mystery of Capital: Why Capitalism Triumphs in the West and Fails Everywhere Else. New York: Basic Books and London: Bantam Press/Random House.

DiMaggio, P. (1988). Interest and agency in institutional theory. In L. Zucker (Ed.), Institutional Patterns and Organizations, pp. 3-22. Cambridge, MA: Ballinger.

Droege, S. and Marvel, M. (2010). Process mechanisms of institutional entrepreneurship. Journal of Developmental Entrepreneurship, Vol 15, no. 2, pp. 205-230. 
Eggertsson, T. (1996). A note on the economics of institutions. In L. Alston, T. Eggertsson and D. North (Eds.), Empirical Studies in Institutional Change: pp. 6-24. Cambridge, UK: Cambridge University Press.

Fligstein, N. (1997). Social skill and institutional theory. American Behavioral Scientist, Vol. 40, no. 4, pp. 397-405.

Garud, R., Jain, S., and Kumaraswamy, A. (2002). Institutional entrepreneurship in the sponsorship of common technological standards: The case of Sun Microsystems and Java. Academy of Management Journal, Vol. 45, no. 1, pp. 196-214.

Garud, R. Hardy, C. and Maguire S. (2007). Institutional entrepreneurship as embedded agency: An introduction to the special issue. Organization Studies, Vol. 28, no. 7, pp. 957-969.

Grant, S. and Humphries, M. (2006). Critical evaluation of Appreciative Inquiry. Action Research, Vol. 4, no. 4, pp. 401-418.

Greenwood, R., Suddaby, R., and Hinings, C. R. (2002). Theorizing change: The role of professional associations in the transformation of institutionalized fields. Academy of Management Journal, Vol. 45, no. 1, pp. 58-80.

Greif, A. (1998). Historical and comparative institutional analysis. American Economic Review, Vol. 88, pp. 80-84.

Harris, R. (1997). Political economy, interest groups, legal institutions and the repeal of the Bubble Act in 1825. Economic History Review. New Series, Vol. 50, pp. 675-696.

Jacobsgaard, M. and Norlund, I. (2011). The impact of Appreciative Inquiry on international development. Al Practitioner Vol. 13. 2, pp. 84-89.

Kraatz, M.and Moore, J. (2002). Executive Migration and Institutional Change. Academy of Management Journal, Vol. 45, No. 1, pp. 120-143.

Little, R. and Rubin, R.. (1987). Statistical Analysis with Missing Data. New York: Wiley and Sons.

Magruder Watkins, J. (2011). Appreciative Inquiry: A global phenomenon. Al Practitioner, Vol. 13 Issue 3, p. 9-11.

Maguire, S., Hardy, C., and Lawrence, T. (2004) Institutional entrepreneurship in emerging fields: HIVIAIDS treatment advocacy in Canada. Academy of Management Journal, Vol. 47, no. 5, pp. 657-679.

Mann, A. (2011). A positive revolution in international development. Al Practitioner, Vol. 13, 3, pp. 12-15.

March, J. and Simon, H. (1958). Organizations. New York: Wiley.

Marshall, T. and Lancaster, C. (2005). Comparing Appreciative Inquiry to action research. Organization Development Journal, Vol. 23, no. 2, pp. 29-49.

Mauro, P. (1995). Corruption and growth. The Quarterly Journal of Economics, Vol. 110, No. 3, pp. 681-712.

Mishra, P. and Bhatnagar, J. (2012), Appreciative Inquiry: Models and applications. Indian Journal of Industrial Relations, Vol. 47, No. 3.

Moore, M., Cangemi, J. and Ingram, J. (2013). Appreciative leadership and opportunity-centric approaches to organization success. Organization Development Journal, Vol. 31, no. 2, pp. 48-53.

Nelson, E. and Wright, C. (2011). Making choices: Simultaneous report and provocative statements, tools for Appreciative Inquiry. Journal of Applied Research for Business Instruction, Vol. 9, no. 1, pp. 1-5.

North, D. (1990). Institutions, institutional change, and economic performance. Cambridge, UK: Cambridge University Press.

North, D. (1991). Institutions. The Journal of Economic Perspectives, 5(1), 97-112.

North, D. and B. Weingast. (1989). The evolution of institutions governing public choice in 17th century England. Journal of Economic History, Vol. 5, pp. 172-200. 
Oliver, C., Fitzgerald, S., and Hoxsey, J. (2011). Critical appreciation of appreciative inquiry: Reflexive choices for shadow dancing. Review of Business Research, Vol. 11, no. ), pp. 4559.

Olson, M. (1965). The Logic of Collective Action: Public Goods and the Theory of Groups. Cambridge, MA: Harvard University Press.

Ostrom, E. (2000). Collective action and the evolution of social norms. The Journal of Economic Perspectives, Vol. 14, No. 3, pp. 137-158

Pacheco, D., York, J., Dean, T., and Sarasvathy, S. (2010). The coevolution of institutional entrepreneurship: A tale of two theories. Journal of Management, Vol. 36, no. 4, pp. 9741010.

Phillips, N. and Tracey, P. (2007). Opportunity recognition, entrepreneurial capabilities, and bricolage: Connecting institutional theory and entrepreneurship in strategic organization. Strategic Organization, Vol. 5, no. 3, pp. 313-320.

Sherer, P. and Lee, K. (2002). Institutional change in large law firms: A resource dependency and institutional perspective. Academy of Management Journal, Vol. 45, no. 1, pp. 102-110.

Shleifer A. and Vishny R. (1993). Corruption. Quarterly Journal of Economics, Vol. 108, no. 3, pp. 599-617.

Tan, E. S. (2005). Ideology, interest groups, and institutional change: The case of the British prohibition of wages in kind. Journal of Institutional Economics, Vol. 1, pp. 175-191

Todaro, M. and Smith, S. (2011). Economic Development. 11th ed., Prentice Hall/Addison-Wesley.

Todnem, R. (2007). Organisational change management: A critical review. Journal of Change Management, Vol. 5, no. 4, pp. 369-380.

Whitney, D. (2010). Appreciative inquiry: Creating spiritual resonance in the workplace. Journal of Management, Spirituality and Religion, Vol. 7, no. 1, pp. 73-88.

Williamson, O. (2000). The new institutional economics: Taking stock, looking ahead. Journal of Economic Literature, Vol. 38, pp. 595-613. 
Studies in Business and Economics no. 14(1)/2019

Appendix: "Equivalent" Commitment Indicators, 2011

Patients and families can rely on University Health System to deliver high quality care and service

Employees are empowered to solve customer/client/patient problems

I feel like my work is meaningful

My job makes good use of my skills/abilities

I have opportunities for personal growth and development in my job

University Health System provides adequate resources to support my career development

I am satisfied with the recognition I receive when I do a good job

University Health System treats employees with respect

I am satisfied with the total benefits package

I am a member of a team that works well together

There is adequate teamwork among my department and other departments

I respect the abilities of my manager

My manager is a good communicator

Overall, I am satisfied with my job

I would recommend University Health System to a friend or relative in need of healthcare services

I am proud to tell people I work for University Health System

How would you rate University Health System as a place to work compared with other companies you know or have heard about?

Given the right opportunity, how likely are you to go work for another organization in the next two years?

\section{Endnotes:}

1 An exception to this is Bushe and Coetzer (1995). Grant and Humphries (2006) propose a critical theory perspective for evaluating Al, while Carter (2006) provides a critique of the usefulness of Al from the nursing field. Other fairly recent critiques include Bushe and Kassam (2005), Marshall and Lancaster (2005), and Bushe (2011).

${ }^{1}$ We were unable to determine the location and cohort for a number of miscoded Round 3 surveys, so they were not counted among the valid observations for that round, leading to smaller sample sizes in both cohorts. Although there is no evidence of a systematic bias in the miscoding, inferences based solely on the Round 3 results should be somewhat qualified. In the language of Little and Rubin (1987), the uncounted data are Missing at Random (MAR). It is possible that the data are Missing Completely at Random (MCAR), although we cannot absolutely verify that this is the case.

${ }^{1}$ See the note above concerning Round 3 data. 